1999-4

\title{
A Comparison of the Use of Tympanic, Axillary, and Rectal Thermometers in Infants
}

\author{
Russell Wilshaw \\ Brigham Young University - Provo \\ Renea L. Beckstrand \\ Brigham Young University - Provo, renea@byu.edu \\ Dawn Waid \\ Brigham Young University - Provo \\ Bruce Schaallje \\ Brigham Young University - Provo
}

Follow this and additional works at: https://scholarsarchive.byu.edu/facpub

Part of the Family Practice Nursing Commons, Maternal, Child Health and Neonatal Nursing Commons, and the Other Nursing Commons

\section{Original Publication Citation}

Wilshaw, R., \& Beckstrand, R. L., Waid, D., \& Schaalje, G. B. (1999). A comparison of the use of tympanic, axillary, and rectal thermometers in infants. Journal of Pediatric Nursing, 14(2), 88-93.

\section{BYU ScholarsArchive Citation}

Wilshaw, Russell; Beckstrand, Renea L.; Waid, Dawn; and Schaallje, Bruce, "A Comparison of the Use of Tympanic, Axillary, and Rectal Thermometers in Infants" (1999). Faculty Publications. 5293.

https://scholarsarchive.byu.edu/facpub/5293

This Peer-Reviewed Article is brought to you for free and open access by BYU ScholarsArchive. It has been accepted for inclusion in Faculty Publications by an authorized administrator of BYU ScholarsArchive. For more information, please contact ellen_amatangelo@byu.edu. 


\title{
A Comparison of the Use of Tympanic, Axillary, and Rectal Thermometers in Infants
}

\author{
Russell Wilshaw, RN, MS, CEN, Renea Beckstrand, RN, MS, CCRN, \\ Dawn Waid, RN, BSN, and G. Bruce Schaalje, PhD
} This study examined the relationship between three instruments used in measuring tympanic, axillary, and rectal temperatures in
infants less than 1 year of age. Temperatures were measured by Oto-temp Pedi Q tympanic thermometers, Becton Dickinson
axillary thermometer, and rectal thermometers. A convience sample of 5 infants less than 90 day and 54 greater than 90 days
with fever, as well as 34 infants less than 90 days and 27 infants greater than 90 days without fever were studied. Correlations of
infants less than 90 days and greater 90 days of age, as well as differences between infant temperature with and without fevers as
variables, were examined. Results indicated a strong statistical relationship between Oto-Temp Pedi Q, Becton Dickinson
axillary temperatures, and rectal temperatures, but not strong enough to base critical clinical decisions. Age and presence or
absence of fever significantly affected the relationships between thermometers.
Copyright 1999 by W.B. Saunders Company

$\mathbf{P}$ RECISE MEASUREMENT of body temperature is essential in a clinical setting when assessing $\mathrm{ill}$ infants under the age of 1 year. Body temperature, the mean measurable heat of the body's metabolism, functions as a significant indicator of an infant's well-being and provides support for nursing assessment and therapeutic management (Glanze, 1988).

Arterial blood temperatures are considered precise measurements of body temperature, but are impractical for routine temperature assessment (Mravinac, Dracup, \& Clochesy, 1989). Calibrated rectal glass mercury thermometers and electronic rectal thermistors have been considered the "gold standard" for obtaining core temperatures (deep tissue temperature) (Kenney, Fortenberry, Surratt, Ribbeck, \& Thomas, 1990; Pransky, 1991). Recent research demonstrates that deep-rectal probes correlate with normal rectal thermometers (Kenney et al., 1990). However, rectal probes are not without disadvantages. Rectal temperature is known to shift slowly and may not accurately reflect changes in situations of flux (Pransky, 1991). Nurses and families consider rectal probes messy, upsetting to infants, and less safe than tympanic thermometers (Alexander \& Kelly, 1991; Barber \& Kilmon,

From Utah Valley Regional Medical Center, Provo, UT; and Brigham Young University, Provo, UT.

Address reprint requests to Russell Wilshaw, RN, MS, CEN,

UVRMC, 1034 North 500 West, Provo, UT 84604.

Copyright $\odot 1999$ by W.B. Saunders Company

0882-5963/99/1402-0004\$10.00/0
1989). Also, rectal thermistor probes take at least 30 to 60 seconds to obtain readings, whereas rectal thermometers take 5 to 8 minutes.

Hospitals and clinics have been using infrared tympanic thermometers, which are considered safe and preferable to rectal and axillary thermometers. Tympanic thermometers measure temperature indirectly from the infrared energy emanating from the tympanic membrane. Because the tympanic membrane and hypothalamus in the brain share their blood supply from the internal and external carotid arteries, the tympanic membrane is an ideal site of measurement. Tympanic temperature thermometers are comfortable and render virtually no complications (Alexander \& Kelly, 1991). Some additional advantages connected with using infrared tympanic thermometers are rapid results, sterility, convenience, and relative lack of risk. Tympanic thermometers scan temperatures in $1 / 2$ to $15 \mathrm{sec}$ onds. There is minimal opportunity for infection and no chance of perforation owing to the short length and diameter of the probe. In infants and children, however, a problem does arise in measuring the infrared energy from the tympanic membrane because at birth, infants have an ear canal diameter of $4 \mathrm{~mm}$; children at age 2 years have an inner ear canal diameter of $5 \mathrm{~mm}$. The probe diameter is $8 \mathrm{~mm}$ (Chamberlain, Gardner, Rubinoff, Klein, Waisman, \& Huey, 1991).

Muma, Treloar, Wurmlinger, Peterson, \& Vitae (1991) expressed concern over inaccuracy with infant subjects whose temperatures were greater 
than $102.9^{\circ} \mathrm{F}$ and with afebrile subjects because of a decrease in accuracy. Correlations for axillary and tympanic thermometers were 0.75 and 0.81 with and without fever for all subjects. Rhoades and Gradner (1990) also demonstrated a correlation of 0.77 for all subjects, but only 7 of 34 subjects had temperatures over $100.4^{\circ} \mathrm{F}$ temperature recorded, and researchers expressed concern for detection of temperature greater than $100.4^{\circ}$.

Rogers, Curley, Driscoll, LeBlanc, Libman, McCarty, and Kerrigan (1991) examined correlations between First Temp tympanic, axillary, and rectal thermometers. Correlations were 0.58 between First Temp and rectal and 0.41 between tympanic and axillary with afebrile pediatric subjects $(\bar{x}=4$ years). Nypaver, Zieserl, Nachtsheim, and Davis (1991) established a correlation of 0.87 between tympanic and rectal thermometers, with mean temperature differences of $-0.35^{\circ} \mathrm{C} \pm 0.45^{\circ} \mathrm{C}$, but $28 \%$ of subjects with fever rectally had no fever tympanically. Weiss, Poetler, and Gocka (1994) found correlations between tympanic and axillary; and rectal temperatures were low, with an $r=0.11$ to 0.31 for left-ear measurements and $r=0.29$ to 0.44 for right-ear measurements.

Muma et al. (1991) reported correlations for axillary temperature measurements compared with rectal for all age groups of 0.75 . Erickson and Woo (1994) also found poor correlation when comparing axillary to bladder temperatures $(0.64)$.

A cause of variation according to Muma et al. (1991) may be the diameter difference between the external auditory meatus ( 4 to $5 \mathrm{~mm}$ ) and probe tip $(8 \mathrm{~mm})$. If the tip does not fit tightly into the canal, the probe may instead register the temperature of skin, external auditory canal, or cerumen. Inadequate sealing of the tympanic thermometer probe in the ear can also produce unreliable readings. Infants' small ear canal diameters of 4 to $5 \mathrm{~mm}$ and Oto Temp LighTouch $8 \mathrm{~mm}$ diameter probes are twice the auditory meatus diameter; therefore, there is restriction of introduction into the canal. Exergen Corporation who manufactures Pedi Q claims the thermometer does not measure temperature optically, but instead searches to measure the warmest site of infrared heat energy being emitted from the auditory canal entrance and predicts a core temperature.

Technique has also been implicated as a cause of temperature reading variations. Chamberlain et al. (1991) found a $0.4^{\circ} \mathrm{F}$ decrease without a downward and backward tug of the ear. Pransky (1991) and Tendrup and Rajk (1992) also detected a $0.23^{\circ} \mathrm{F}$ increase with a backward ear tug and $0.36^{\circ} \mathrm{F}$ increase with meticulous probe placement.

Henker and Coyne (1995) found a poor (0.19) correlation between tympanic and pulmonary artery temperature readings with adult subjects. Researchers reasoned differences in room temperature could generate variations in the temperature of blood that perfuses the tympanic membrane. Tympanic membranes are predominately supplied by surface vessels from the external carotid. This could easily affect ambient temperatures of the membrane. In addition, findings indicate the tympanic membrane and external auditory meatus measurements are influenced by facial cooling and wind condition, but rectal temperatures are not.

Finally, infant temperatures are acknowledged to be less stable and may change rapidly (Muma et al., 1991; Pransky, 1991; Shiraki, Konda, \& Sagawa, 1986). Rectal temperatures may not reflect these sorts of changes; therefore rectal temperature may not accurately reflect infant's core temperatures.

Ototemp LighTouch Pedi Q tympanic thermometer is the first tympanic (ear) thermometer specifically designed for infant subjects (Exergen Corp., 1994). Other thermometers for infant use are the B-D Flexible Digital thermometers and glass mercury rectal thermometers. Both are extremely inexpensive and available to outpatient clinics and emergency departments.

Ototemp LighTouch Pedi Q tympanic and B-D Flexible Digital for axillary temperature have never been investigated to determine precision when measuring temperature compared with calibrated mercury rectal thermometers in infants less than 1 year of age with and without fever. Also, infants less than 90 days and greater than 90 days of age were studied to discern whether there was a difference in temperatures measured because of the small auditory canal. If a tympanic thermometer or axilla thermometer demonstrates an ability to be as precise, rapid, safer, easier, and cleaner than a rectal thermometer, it would benefit clients, families, and nurses who assess infants.

\section{METHOD}

A convience sample of 59 infant subjects under the age of 1 year who presented at a western community clinic with fever were used as one group. A second convenience sample of 61 infant subjects under the age of 1 year without fever from a western community clinic were also studied. Prior approval from the Investigational Review Board for the protection of human subjects was 
obtained. All guardians gave written informed consent.

Three instruments were used to measure temperature with infants under the age of 12 months: Ototemp LighTouch Pedi Q tympanic thermometer (Exergen Corp., Newton, MA), which automatically registers oral temperature (Pedi Q), a B-D Flexible digital thermometer (B-D) (Westminister, $\mathrm{SC}$ ) for axillary temperatures, and a single calibrated mercury rectal thermometer. All instruments were calibrated according to manufacturers' specifications before and after commencement of the investigation. Ototemp LighTouch Pedi Q was calibrated with a black-body immersed in a temperature controlled bath to 98.6 and $104^{\circ} \mathrm{F}$ and compared with a certified mercury thermometer. The B-D Flexible digital thermometer and mercury glass thermometer were also calibrated in controlled temperature bath against a certified mercury thermometer to plus or minus $0.1^{\circ} \mathrm{F}$.

Temperatures were obtained by one researcher who at the beginning of the study received comprehensive training on obtaining tympanic, axillary, and rectal temperatures. Tympanic temperatures were always obtained first, by meticulously pointing probes toward the tympanic membrane when obtaining measurements. Proper technique was accomplished by an upward and backward pull of the pinna by the researcher to straighten the canal. Right or left ear order was determined by a flip of the coin. Axillary temperatures were always taken second for 8 minutes and obtained within 1 minute after completion of tympanic measurements. Rectal temperatures were always taken last within 1 minute of completion of the axillary temperature, by placing the probe 1 inch into the rectum for a minimum of 5 minutes and within 10 minutes of completion of the tympanic temperature readings. The order of tympanic, axillary, and rectal temperatures was selected to decrease subject agitation with the rectal temperature last. Temperature readings were documented in degrees Fahrenheit. Fever was defined as a rectal temperature of greater than $99.6^{\circ} \mathrm{F}$ (Klein, Schlesinger, \& Karasic, 1984; Steadman's Medical Dictionary, 1993; Wunderlich, 1868).

A Pearson's correlation coefficient was computed to determine the degree of similarity between temperature readings when using a Pedi-Q tympanic thermometer, a B-D Flexible digital thermometer for axillary temperature, and a calibrated mercury rectal thermometer for all subjects. A Pearson correlation coefficient was also used to separately analyze this same data for children less than and greater than 90 days of age. Regression analysis was used to determine if the relationship between the Pedi $Q$ and rectal temperatures and B-D and rectal temperatures was affected by age, fever, gender, or which ear was measured. Finally, sensitivity and specificity were calculated for fever at a temperature of greater than $99.6^{\circ}$ and $100.4^{\circ} \mathrm{F}$ rectally.

\section{RESULTS}

A total of 120 infants, 59 with and 61 without fever, were studied. In all 39 infants were younger than 90 days of age, and 81 subjects were older than 90 days of age. Gender distribution was 70 males and 50 females. Descriptive statistics are listed in Table 1.

Overall mean temperature was $99.5^{\circ} \mathrm{F}$ for Oto Temp Pedi Q, $98.3^{\circ} \mathrm{F}$ for Becton Dickinson, and $99.8^{\circ} \mathrm{F}$ for rectal thermometers. Temperatures ranged from 97.0 to $104.5^{\circ} \mathrm{F}, 94.8$ to $102.3^{\circ} \mathrm{F}$, and 98.6 to $103.0^{\circ} \mathrm{F}$ for Oto Temp, Becton Dickinson, and rectal thermometers, respectively. Standard deviations were $1.11,1.01$ and 0.75 for tympanic, axillary and rectal respectively.

For all infants, a moderate positive correlation was found between the Pedi-Q and rectal thermometry, as well as the B-D thermometer using the axillary route and rectal thermometry. All $P$ values were $<.005$. (Table 2, All Subjects). When Oto Temp Pedi $Q$ was compared with the Becton Dickinson axillary thermometer, the $\mathrm{r}$ was 0.45 for all subject and 0.54 for subjects greater than 90 days, with a $P<.001$. No significance was found for infants less than 90 days.

Infants less than 90 days of age demonstrated no significant correlation between Pedi-Q and rectal temperatures. Correlations between Pedi $Q$ and rectal temperature for infants greater than 90 days were moderate. For B-D axillary and rectal temperatures, correlation coefficients were moderate for infants less than 90 day and moderate for infants greater than 90 days, with $P$ values of $<.0001$ (Table $2,<90$ days and $>90$ days).

Regression analysis indicated the relationship between Pedi $\mathrm{Q}$ and rectal temperature was not affected by ear side $(\mathrm{F}=.07, P>.05)$ or gender $(\mathrm{F}=.61, P>.05)$. However, age and fever had significant effects on the relationship $(F=5.26$,

Table 1. Descriptive Statistics for Age

\begin{tabular}{lcrl}
\hline & Months & \multicolumn{1}{c}{ SD } & Range \\
\hline All subjects & 19.6 & 12.00 & $1-44$ \\
Fever & 26.0 & 9.57 & $7-44$ \\
Without fever & 13.8 & 10.65 & $1-44$ \\
\hline
\end{tabular}

Note: $(N=120)$ Data displayed in weeks. 
Table 2. Correlations of Oto Jemp Pedi Q, Becton Dickenson, and Rectal Temperatures

\begin{tabular}{lccc}
\hline & $\begin{array}{c}\text { All Subjects } \\
(N=120)\end{array}$ & $\begin{array}{c}<90 \text { Days } \\
(n=39)\end{array}$ & $\begin{array}{c}>90 \text { Doys } \\
(n=81)\end{array}$ \\
\hline Machine & $r$ & $r$ & $r$ \\
Oto Temp Pedi $Q$ & .47 & N.S. & .70 \\
Becton Dickenson & .53 & .48 & .61 \\
\hline
\end{tabular}

$P<.005$.

$P<.05$ for age and $\mathrm{F}=11.52, P<.001$ for fever). Older infants had a $0.81^{\circ} \mathrm{F}$ increase in rectal temperature compared with younger infants. The slopes of the relationship between Pedi-Q and rectal temperature (Table 3 ) indicate that, for nonfebrile infants, a $1^{\circ} \mathrm{F}$ change in the rectal temperature is associated with negligible changes in Pedi $\mathrm{Q}$ temperatures. For febrile children, a $1^{\circ} \mathrm{F}$ change in rectal temperature is associated with approximately a $1.5^{\circ} \mathrm{F}$ increase in Pedi $\mathrm{Q}$ temperature.

Results of the regression analysis were not significant for gender and fever when comparing Becton Dickinson to the rectal thermometer. Age has a significant effect on temperature $(F=10.33$, $P<.001$ ). Axillary temperatures were $0.48^{\circ} \mathrm{F}$ lower for infants greater than 90 days compared with infants less than 90 days for any given rectal temperature.

Sensitivity is the ability of the thermometer to detect a fever when fever is present. Sensitivity values for infants with rectal temperatures of greater than $99.6^{\circ} \mathrm{F}$ for all classes of subjects except infants greater than 90 days were moderate for Oto Temp Pedi Q. Specificity for infants greater than 90 days was poor. Specificity is the ability of the thermometer to not detect a fever when fever is not present. Specificity values were poor for all classes except infants greater than 90 days for the Oto Temp in this category. Specificity was moderate for infants greater than 90 days. Becton Dickenson digital thermometer's sensitivity was moderate for all classes, and specificity was weak for all classes (Table 4).

When sensitivity and specificity values were calculated for rectal temperatures greater than $100.4^{\circ} \mathrm{F}$, Oto Temp Pedi Q sensitivity was $100 \%$ for all categories, and specificity improved to the fair

\begin{tabular}{|c|c|c|c|}
\hline Age & Fever & Slope of Regression & S.E. \\
\hline \multirow[t]{2}{*}{ Young } & No & -0.59 & 0.49 \\
\hline & Yes & 1.46 & 0.35 \\
\hline \multirow[t]{2}{*}{ Old } & No & 0.35 & 0.66 \\
\hline & Yes & 1.51 & 0.15 \\
\hline
\end{tabular}

to moderate range. The Becton Dickinson product sensitivity remained moderate except for infants less than 90 days where sensitivity was $100 \%$, and specificity improved to the fair to moderate range. However, in infants less than 90 days, there was only one reading in the fever range as measured by the Becton Dickinson thermometer, producing the $100 \%$ sensitivity (Table 4).

Standard deviations of the errors of measurement of the various thermometers are an indication of reliability of the thermometers (Table 5). Oto Temp and B-D had lower reliability than the rectal thermometer. Rectal reliability was greater for children over 90 days than for younger children.

\section{DISCUSSION}

The intent of this study was to determine the relationship between the temperature in infants under 1 year of age as measured by Oto Temp LighTouch Pedi Q tympanic thermometers, B-D Flexible digital thermometers for axillary temperature, and a calibrated rectal thermometer. Correlations between Oto Temp Pedi Q, Becton Dickinson $B-D$, and rectal temperatures were all moderately to strongly positive, ranging from an $r=0.47$ to 0.70 . Even though a positive physiological correlation exists, basing clinical decisions of treatment with critically ill infants should be questioned.

There is an explanation for lack of a strong physiological correlation. Oto Temp Pedi $Q$ and Becton Dickinson B-D thermometers recorded higher temperatures in general. Correcting for rectal temperature, Pedi-Q registered $0.7^{\circ} \mathrm{F}$ and B-D $0.5^{\circ} \mathrm{F}$ higher on average. Pedi $Q$ recorded fever $96(80 \%)$ times and B-D $86(72 \%)$ times, whereas the rectal thermometer registered fever only 59 times (49\%). Inflation of temperature would lead to unnecessary septic workup with infants, but the argument could be made that septic workups are preferable to failure to detect fever when fever exists. When low-grade fevers $\left(<100.2^{\circ} \mathrm{F}\right)$ were detected with the rectal thermometer, Oto-Temp Pedi did not register a fever seven times $(11.8 \%)$ and B-D axillary did not measure fever nine times (15.2\%). Inability to detect fever is a much more serious consequence.

Lack of high-grade fever may also have affected the results. Of the 120 subjects, only 11 rectal temperatures, 6 tympanic, and 2 axillary temperatures were above $101^{\circ} \mathrm{F}$. Ninety-nine percent of fevers using tympanic and rectal thermometers and $100 \%$ of axillary would not be considered high grade $\left(<103^{\circ} \mathrm{F}\right)$. Low correlations may have been the result of a limited range of temperatures, with a 
Table 4. Sensitivity and Specificity of Oto Temp Pedi Q and Becion Dickenson When Screening for Fever

\begin{tabular}{|c|c|c|c|c|c|c|}
\hline \multirow[b]{2}{*}{$\mathrm{FEV} \rightarrow 99.6$ rectal } & \multicolumn{2}{|c|}{ All Subjects } & \multicolumn{2}{|c|}{$<90$ Days } & \multicolumn{2}{|c|}{$>90$ Days } \\
\hline & & & & & & \\
\hline Machine & Sensitivity $(n)$ & Speciticity $(n)$ & Sensitivity $(n)$ & Specificity $(n)$ & Sensitivity $(n)$ & Specificity $(n)$ \\
\hline Oto Temp Pedi Q & $.83(59)$ & $.20(61)$ & $.80(5)$ & $.02(34)$ & $.41(54)$ & $.83(27)$ \\
\hline Becton Dickenson & $.81(59)$ & $.31(61)$ & $.80(5)$ & $.21(34)$ & $.82(54)$ & $.44(27)$ \\
\hline \multicolumn{7}{|l|}{$\mathrm{FEV} \rightarrow 100.4$ rectal } \\
\hline Machine & Sensitivity ( $n$ ) & Specificity / $n$ & Sensitivity $(n)$ & Specificity / $n$ & Sensitivity (n) & Specificity $(n)$ \\
\hline Oto Temp Pedi $Q$ & $1.00(16)$ & $.58(104)$ & $1.00(1)$ & $.34(38)$ & $1.00(15)$ & $71(66)$ \\
\hline Becton Dickenson & $.75(16)$ & $.64(104)$ & $1.00(1)$ & $.58(38)$ & $.82(15)$ & $.44(66)$ \\
\hline
\end{tabular}

larger percentage of low-grade fevers in this homogeneous sample of infants (Weiss et al., 1994). If the population sample had more diversity with higher fever readings, results may have been different.

Results of a regression analysis showed differences between infant temperature when fever and age were considered. Oto Temp Pedi Q tympanic thermometer displayed significantly more variation than rectal thermometers when subjects presented with fever and were greater than 90 days old. As temperature rose into the fever range when measured with a rectal thermometer, Oto Temp measurements increased disproportionately higher. Temperatures of subjects older than 90 days were also higher when adjusted to rectal temperature. Nurses should question the accuracy of readings with infants greater than 90 days and with fever. False high readings may lead to unnecessary treatment. Findings also indicated no significant variation in temperature measurement when ear order or gender was considered.

Regression analysis of the B-D and rectal thermometers for age demonstrated a decrease in temperature with increased age compared with younger infants. This may be due to older infants" ability to wiggle more than a young infant. When using the axillary route, nurses need to control more for movement.

Sensitivities for Oto-temp Pedi Q were moderate ( 0.80 to 0.82 ) with rectal temperatures of greater than $99.6^{\circ} \mathrm{F}$, and increased to $100 \%$ when temperature was $100.4^{\circ} \mathrm{F}$. Moderate to high sensitivity by the tympanic thermometer may be due to Ototemp

Table 5. Standard Deviations of the Measurement Errors

\begin{tabular}{ccc}
\hline Thermometer & Age & SD \\
\hline Oto Temp Pedi $Q$ & $<90$ days & 0.81 \\
& $>90$ days & 0.88 \\
B-D axillary & $<90$ days & 0.77 \\
& $>90$ days & 0.79 \\
Rectal & $<90$ days & 0.71 \\
& $>90$ days & 0.24 \\
\hline
\end{tabular}

detecting the highest temperature in the ear canal, as observed by low specificity ( 0.34 to 0.71 ) when sensitivity was $100 \%$. Sensitivity was also moderate for all categories of B-D digital axillary, except for infants less than 90 days old; only one infant had a fever $(100 \%)$. Specificity ranged from 0.21 to 0.64 . Again, this may be due to overdetection of fever as measured by the tympanic thermometer or a slow change in measurement of core temperature by the rectal thermometer.

Sensitivity in detecting fever for axillary and tympanic sites was 0.48 and 0.55 , respectively (Muma et al., 1991). Yaron, Lowenstein, KoziolMcLain, and Murphy (1992) reported a sensitivity of only $54 \%$ with tympanic thermometers when detecting a significant fever $\left(\mathrm{RT}>101.5^{\circ} \mathrm{F}\right)$. At a rectal thermometer temperature of $101.0^{\circ} \mathrm{F}$, tympanic sensitivity and specificity were $68 \%$ and 96\%, respectively (Tenderup \& Milewski, 1991).

\section{Limitations}

The majority of subjects had low-grade fevers as defined by their rectal temperature. Less than half the subjects with fever had temperatures above $100.2^{\circ} \mathrm{F}$. A larger population of children with high-grade fever is needed. Subjects' data collection was not randomly collected. Also, one researcher collected all data and was not blinded to temperature readings. Efforts were not aimed at regulating surrounding variables such as ambient temperature, quantity of clothes and blankets, or amount of infant movement (Weiss et al., 1994). Finally, infants' ears were not checked for cerumen or otitis media even though researchers have demonstrated no variation with tympanic readings (Chamberlain et al., 1991).

\section{Significance for Nursing}

OtoTemp LighTouch and Becton Dickenson digital thermometers show a correlation, but it is not strong enough to use as a basis for clinical treat- 
ment. Clinicians must realize that both instruments tend to register readings higher than rectal thermometers, and diagnostic testing and pharmacological treatment may not be necessary.

Findings from this research indicate that OtoTemp LighTouch and Becton-Dickenson digital thermometers should be used with caution in infants under the age of 1 year as a basis for clinical decisions among critically ill infants. Nurses need to know that speed and convenience do not neces- sarily mean accuracy when dealing with febrile infants. More research needs to be done to verify the accuracy of this study.

Recommendations for additional research on this topic are as follows: (1) duplicate investigation with larger population samples with higher fevers, (2) check rectal temperature 30 minutes to 1 hour later if tympanic temperatures are higher than rectal temperatures, and (3) conduct studies at height of fever season (December through March).

\section{REFERENCES}

Alexander, D., \& Kelly, B. (1991). Responses of children, parents and nurses to tympanic thermometry in the pediatric office. Clinical Pediatrics, 30 (suppl. 4), 53-56.

Barber, N., \& Kilmon, C.A. (1989). Reaction to tympanic temperature measurement in an ambulatory setting. Pediatric Nursing, 15, 477-481.

Chamberlain, J.M., Gardner, J., Rubinoff, J.L., Klein, B.L., Waisman, Y., \& Huey, M. (1991). Comparison of a tympanic thermometer to rectal and oral thermometers in a pediatric emergency department. Clinical Pediatrics, 30 (Suppl. 4), 24-29.

Exergen Corporation. (1994): The Ototemp LighTouch Reference Book. Newton, MA.

Erickson, R., \& Woo, T. (1994). Accuracy of infrared ear thermometry and traditional temperature methods in young children. Heart \& Lung, 23, 181-195.

Glanze, W. (Ed.), (1988). Mosby's medical and nursing dictionary. St. Louis: C.V. Mosby Company.

Henker, R., \& Coyne, C. (1995). Comparison of peripheral temperature measurements with core temperature. AACN Clinical Issues, 6, 21-30.

Kenney, R.D., Fortenberry, J.D., Surratt, S.S., Ribbeck, B.M., \& Thomas, W.J. (1990). Evaluation of an infrared tympanic membrane thermometer in pediatric patients. Pediatrics, 85 (5), 854-858.

Klein, J., Schlesinger, P., \& Karasic, R. (1984). Management of the febrile infant three months of age or younger. Pediatric Infectious Disease, 3 (1), 75-79.

Mravinac, C.M., Dracup, K., \& Clochesy, J.M. (1989). Urinary bladder and rectal temperature monitoring during clinical hypothermia. Nursing Research, 38 (2), 73-76.

Muma, B., Treloar, D., Wurmlinger, K., Peterson, E., \& Vitae, A. (1991). Comparison of rectal, axillary, and tympanic membrane temperatures in infants and young children. Annals of Emergency Medicine, 64, 41-44.
Nypaver, M., Zieserl, B., Nachtsheim, B., \& Davis, A. (1991). American Joumal of Disease of Children, 145, Abstract No. 403.

Pransky, S.M. (1991). The impact of technique and conditions of the tympanic membrane upon infrared tympanic thermometry. Clinical Pediatrics, 30 (Suppl. 4), 50-52.

Rhoads, F.A., \& Grander, J. (1990). Assessment of an oral infrared sensor for body temperature measurement in children. Clinical Pediatrics, 29 (2), 112-115.

Rogers, J., Curley, M., Driscoll, J., LeBlanc, G., Libman, M., McCarty, K., \& Kerrigan, T. (1991). Evaluation of tympanic membrane thermometer for use with pediatric patients. Pediatric Nursing, 17, 376-378.

Shiraki, K., Konda, N., \& Sagawa, S. (1986). Esophageal and tympanic temperature responses to core blood temperature changes during hyperthermia. Journal of Applied Physiology, 61, 98-102.

Steadman's medical dictionary. (25th ed.). (1993). Baltimore, MD: Williams \& Wilkins.

Tenderup, T., \& Milewski, A. (1991). The performance of tympanic thermometers in a pediatric emergency department Clinical Pediatrics, 30 (Suppl. 4), 18-23.

Terndrup, T., \& Rajk, J. (1992). Impact of operator technique and device on infrared emission detection tympanic thermom etry. Journal of Emergency Medicine, 10, 683-687.

Weiss, M., Poetler, D., \& Gocka, I. (1994). Infrared tympanic thermometry for neonatal temperature assessment. Journal of Obstetrical Gynecological Neonatal Nursing, 23, 798-804.

Wunderlich, C. (1868). Das verhalten der eiaenwarne in Krankenheiten. Leipzig, Germany: Otto Wigard.

Yaron, M., Lowenstein, J., Koziol-McLain, J., \& Murphy, J. (1992). Inaccuracy of the infrared tympanic thermometer in the emergency department. Annals of Emergency Medicine, 21, 237. 